\title{
The Level of Knowledge of Pelvic Floor Dysfunction After Delivery in Women who Attended to a Tertiary Center
}

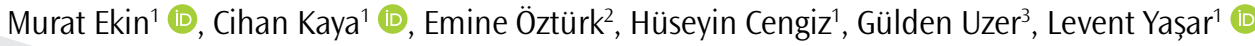

Objective: Pelvic floor disorders affect women in all age groups and cause poor quality of life with economic burden. The aim of the present study was to investigate the attitude of women who were admitted to our clinic about the relationship between mode of delivery and pelvic floor disorders and pelvic muscle exercises.

Methods: A total of 1316 women who had attended our outpatient gynecology clinic for various complaints were interviewed by an expert gynecologist. Demographic data including age, marital status, education, health insurance, menopausal status, parity, mode of deliveries, birth weights, and also lower urinary tract symptoms were included in the interview. All the participants were asked to complete a verbal modified Pelvic Risk Knowledge Score (PRKS) questionnaire regarding their knowledge about pelvic floor disorder risks.

Results: The mean modified PRKS was 4.95 \pm 2.5 . Of the patients, $26.8 \%$ had a diagnosis of stress urinary incontinence, $14.3 \%$ had urgency, $19.8 \%$ had frequency, $11.1 \%$ had >stage 2 pelvic organ prolapse (POP), $7.4 \%$ did not even hear about pelvic muscle exercises, and $17.6 \%$ did not even inform about pelvic muscle exercises by a health care provider. PRKS was significantly higher in multiparous women than in primiparous women $(p<0.0001)$. Vaginal birth also significantly increased the PRKS with respect to cesarean delivery $(p=0.006)$. Women with cesarean deliveries had significantly increased PRKS with respect to nulliparous women $(p<0.0001)$.

Conclusion: Episiotomy, menopause, lower urinary tract symptoms, and POP are the factors that significantly increase PRKS.

Keywords: Pelvic floor disorders, pelvic muscle exercises, pelvic risk, vaginal birth

The abstract of this paper has been presented as a poster presentation in $1^{\text {st }}$ UHS Congress of Pelvic Floor Disorders, 5-7 May 2017, istanbul, Turkey.

ORCID IDs of the authors: M.E. 0000-0002-45255125; C.K. 0000-0003-4175-7694; L.Y. 0000-00028679-2699.

'Department of Gynecology and Obstetrics, Health Sciences University Bakırköy Dr. Sadi Konuk Training and Research Hospital, istanbul, Türkiye ${ }^{2}$ Clinic of Gynecology and Obstetrics, İstanbul Bahçelievler State Hospital, İstanbul, Türkiye 3Üsküdar Doğancilar Family Health Center, İstanbul, Türkiye

\section{Address for Correspondence:}

Cihan Kaya, Department of Gynecology and Obstetrics, Health Sciences University Bakırkoy Dr. Sadi Konuk Training and Research Hospital, İstanbul, Türkiye

E-mail: drcihankaya@gmail.com

Received: 23.10.2017

Accepted: 22.02.2018

(C) Copyright 2018 by Available online at istanbulmedicaljournal.org

\section{Introduction}

Pelvic floor disorders affect women in all age groups and cause poor quality of life and economic burden (1). Cross-sectional studies suggest that women who had vaginal birth are more susceptible to urinary incontinence, fecal incontinence, pelvic organ prolapse (POP), and sexual dysfunction than women who had only cesarean deliveries later in life $(2,3)$. Pelvic floor muscle exercise is defined as the repetitive selective, voluntarily contraction and relaxation of the pelvic muscles. It aims to strengthen the pelvic muscles to support the urethra and increase the urethral sphincteric function (4). It has been established that pelvic floor muscle exercises decrease urinary incontinence in pregnancy, postpartum period, and later in life. It also reduces the episodes of postpartum fecal incontinence and improves sexual dysfunction in the postpartum period (5-7).

The aim of the present study was to investigate the perception of women on the relationship between mode of delivery and pelvic floor disorders and to investigate the knowledge on pelvic floor muscle exercises.

\section{Methods}

This was a cross-sectional observation study. Ethics committee approval was received for this study from the Ethics Committee of Health Sciences University Bakirköy Dr. Sadi Konuk Training and Research Hospital (2014/27). Written informed consent was obtained from all of the participants. Overall, 1316 women who had attended the outpatient gynecology clinic for various complaints were interviewed by an expert gynecologist. Demographic data including age, marital status, education, health insurance, menopausal status, parity, mode of deliveries, birth weights, and lower urinary tract symptoms were included in the interview. The clinical examination data for the presence of episiotomy, stress urinary incontinence (SUI), urgency, frequency, and POP were recorded.

All of the participants were asked to complete a verbal modified Pelvic Risk Knowledge Score (PRKS) questionnaire adapted from Dunbar et al. (8) regarding their knowledge about pelvic floor risks associated with the delivery methods and their awareness about the pelvic muscle exercises 
(Table 1). For analysis of the awareness of the risk of vaginal delivery (a nine-item questionnaire), addressing this topic were scored along each subject's number of deliveries. For the yes/no questions, a score of 1 was assigned to "Yes" response and 0 to "No" response. Vaginal responses were scored as 1 , and cesarean responses as 0 . Then, a composite risk score modified PRKS was obtained by adding all of the scores along with 10 items of the number of deliveries. A PRKS of 0 indicates no knowledge, whereas higher scores indicate a higher level of knowledge on a linear scale.

\section{Statistical Analysis}

The Number Cruncher Statistical System 2007 statistical software (NCSS, UT, USA) was used for data analysis. Descriptive statistical analysis was expressed as mean \pm standard deviation. One-way analysis of variance was used for normally distributed data. The Tukey test was used for post hoc analysis of parametric data. A paired sample t-test and the chi-square test were used for comparison of qualitative and quantitative data. A univariate model was created to determine the effect of episiotomy, menopause, SUI, urgency, frequency, and POP on PRKS. A Spearman correlation analysis was performed to determine any correlation between parity and PRKS. A $p<0.05$ was accepted as statistically significant.

\section{Results}

Table 2 shows the demographic and clinical examination findings of the patients. The mean modified PRKS was 4.95 \pm 2.5 . Among the patients, $26.8 \%$ were diagnosed with SUI, $14.3 \%$ had urgency, $19.8 \%$ had frequency symptoms, and $11.1 \%$ had $>$ stage 2 POP at pelvic examination. Table 3 shows the responses that were given to a nine-item questionnaire by the patients. The responses to questions 8 and 9 were $7.4 \%$ and $17.6 \%$, respectively, indicating that awareness of pelvic muscle exercises is really poor and health care providers hardly inform their patients about pelvic muscle exercises. For univariate analysis, presence of episiotomy, menopause, SUI, urgency, frequency and POP were the

\section{Table 1. Questionnaire items: Pelvic risk knowledge score}

1. In your opinion, does a vaginal delivery (natural childbirth) increase your risk of problems controlling your bladder (difficulty holding your water)? Yes/No

2. In your opinion, does a cesarean delivery increase your risk of problems controlling your bladder (difficulty holding your water)? Yes/No

3. In your opinion, which type of delivery could cause more harm to pelvic floor? Vaginal/cesarean

4. In your opinion, does a vaginal delivery (natural childbirth) increase your risk of problems controlling your bowels (leakage of gas and stool)? Yes/No

5. In your opinion, does a vaginal delivery have a negative effect on your sexual function? Yes/No

6. In your opinion, does a cesarean delivery have a negative effect on your sexual function? Yes/No

7. In your opinion, can exercises of the muscles in your pelvic area help lessen the chance of your developing bladder and/or bowel problems later in life? Yes/No

8. Have you ever heard about pelvic muscle exercises? Yes/No

9. Have you ever informed about or suggested to make pelvic muscle exercises to a health care provider? Yes/No factors that significantly increase the PRKS $(p<0.0001)$ (Table 4). There was a significant correlation between parity and PRKS $(p<0.0001)$. PRKS was higher in nulliparous women than in primiparous women $(p<0.001)$. It was also significantly higher in multiparous women than in primiparous women $(p>0.0001)$ (Table 5). Vaginal birth was also significantly increased in the PRKS with respect to cesarean delivery $(p=0.006)$, but women who had cesarean deliveries had also significantly higher PRKS than nulliparous women $(p<0.0001)$ (Table 6).

\begin{tabular}{|c|c|c|}
\hline & $\min -\max$ & mean $\pm S D$ \\
\hline Age & $14-81$ & $43.27 \pm 12.39$ \\
\hline Parity & $0-13$ & $2.22 \pm 1.8$ \\
\hline Vaginal birth & $0-13$ & $1.95 \pm 1.87$ \\
\hline Cesarean birth & $0-4$ & $0.28 \pm 0.62$ \\
\hline PRKS & $0-18$ & $4.95 \pm 2.5$ \\
\hline
\end{tabular}

n

\begin{tabular}{|c|c|c|c|}
\hline & & $\mathrm{n}$ & $\%$ \\
\hline \multirow[t]{3}{*}{ Number of deliveries $>4000 \mathrm{~g}$} & 0 & 1.142 & 86.8 \\
\hline & 1 & 147 & 11.2 \\
\hline & $\geq 2$ & 27 & 2.1 \\
\hline \multirow[t]{3}{*}{ Number of operative delivery } & 0 & 1.263 & 96.0 \\
\hline & $\geq 1$ & 31 & 2.4 \\
\hline & $\geq 2$ & 22 & 1.7 \\
\hline \multirow[t]{2}{*}{ Episiotomy } & No & 780 & 59.3 \\
\hline & Yes & 536 & 40.7 \\
\hline \multirow[t]{4}{*}{ Marital status } & Married & 1.079 & 82.0 \\
\hline & Single & 107 & 8.1 \\
\hline & Divorced & 69 & 5.2 \\
\hline & Widow & 61 & 4.6 \\
\hline \multirow[t]{2}{*}{ Menopause } & No & 835 & 63.4 \\
\hline & Yes & 481 & 36.6 \\
\hline \multirow[t]{4}{*}{ Educational status } & Illiterate & 127 & 9.7 \\
\hline & Primary school & 818 & 62.2 \\
\hline & High school & 238 & 18.1 \\
\hline & University & 133 & 10.1 \\
\hline \multirow[t]{2}{*}{ Health insurance } & None & 65 & 4.9 \\
\hline & Yes & 1.251 & 95.1 \\
\hline \multirow[t]{2}{*}{ Stress urinary incontinence } & No & 963 & 73.2 \\
\hline & Yes & 353 & 26.8 \\
\hline \multirow[t]{2}{*}{ Urgency } & No & 1.128 & 85.7 \\
\hline & Yes & 188 & 14.3 \\
\hline \multirow[t]{2}{*}{ Frequency } & No & 1.056 & 80.2 \\
\hline & Yes & 260 & 19.8 \\
\hline \multirow[t]{2}{*}{ Pelvic organ prolapse (>stage 2 ) } & No & 1.170 & 88.9 \\
\hline & Yes & 146 & 11.1 \\
\hline
\end{tabular}

PRKS: pelvic risk knowledge score; min: minimum; max: maximum; SD: standard deviation 


\section{Discussion}

Women's attitude on vaginal delivery differs in different parts of the world in relation to traditions and socioeconomic status. The reasons for selecting preferentially vaginal delivery in a Turkish population include fear of surgery, desire of early recovery, and request for having a great number of children (9). In the present study, $49 \%$ and $68 \%$ of women were unaware that vaginal birth can cause urinary incontinence and fecal incontinence later in life, respectively. Only $37 \%$ of women thought that pelvic muscle exercises could help decrease the chance of developing bladder and

Table 3. The responses that were given to a nine-item questionnaire by the patients

\begin{tabular}{|cccc}
\hline & & $\mathbf{n}$ & $\%$ \\
\hline Question 1 & No & 648 & 49.2 \\
\hline Question 2 & No & 668 & 50.8 \\
\hline Question 3 & Yes & 250 & 19.0 \\
\hline Question 4 & Vaginal & 562 & 42.7 \\
\hline Question 5 & Cesarean & 754 & 57.3 \\
\hline Question 6 & No & 896 & 68.1 \\
\hline Question 7 & Yes & 420 & 31.9 \\
\hline & No & 896 & 68.1 \\
\hline Question 8 & Yes & 420 & 31.9 \\
\hline Question 9 & No & 1.064 & 80.9 \\
\hline Yes & 252 & 19.1 \\
\hline No & 488 & 37.1 \\
\hline Yes & 828 & 62.9 \\
\hline No & 1.084 & 82.4 \\
\hline Yes & 232 & 17.6 \\
\hline No & 1.219 & 92.6 \\
\hline & Yes & 97 & 7.4 \\
\hline
\end{tabular}

Table 4. The univariate analysis of PRKS and episiotomy, menopause, SUI, urgency, frequency, and POP

\begin{tabular}{llccc} 
& & $\mathbf{n}$ & PRKS & $\mathbf{p}$ \\
\hline Episiotomy & No & 780 & $4.71 \pm 2.74$ & 0.0001 \\
\hline Menopause & Nos & 536 & $5.3 \pm 2.04$ & \\
\hline & Yes & 483 & $4.53 \pm 2.35$ & 0.0001 \\
\hline SUI & No & 963 & $5.68 \pm 2.58$ & \\
\hline & Yes & 353 & $6.91 \pm 2.39$ & \\
Urgency & No & 1128 & $4.59 \pm 2.29$ & 0.0001 \\
\hline & Yes & 188 & $7.08 \pm 2.62$ & \\
\hline Frequency & No & 1056 & $4.53 \pm 2.27$ & 0.0001 \\
\hline & Yes & 260 & $6.66 \pm 2.67$ & \\
\hline POP & No & 1170 & $4.66 \pm 2.32$ & 0.0001 \\
\hline & Yes & 146 & $7.28 \pm 2.63$ & \\
\hline
\end{tabular}

PRKS: pelvic risk knowledge score; SUI: stress urinary incontinence; POP: pelvic organ prolapse bowel problems later in life. Among women, $82 \%$ did not even hear about pelvic muscle exercises. The present study suggested that there is an important lack of knowledge about the relationship between vaginal birth and pelvic floor disorders. In a previous review, pelvic floor muscle exercises significantly prevent urinary incontinence in late pregnancy and postpartum for the continent women before pregnancy (10). Consistent with these findings, another review of 22 trials by Boyle et al. (6) with 8484 pregnant or postpartum women revealed that continent pregnant women who had intensive antenatal pelvic floor muscle exercises are less likely to report urinary incontinence in late pregnancy and at 6 months of postpartum period. Pelvic muscle exercises are recommended as the first-line management for the prevention of SUI during pregnancy and postpartum period. In addition, the National Institute for Health and Care Excellence suggests pelvic floor muscle exercises to all pregnant women for the prevention of SUI (5). According to the given results to the questions related with pelvic muscle exercises, Turkish women were poorly aware of these exercises, and health care providers were reluctant to inform and teach their patients for this common health burden.

In the present study, we have observed that aging, menopause, having episiotomy, lower urinary tract symptoms, and POP were significantly related with higher PRKS. This result can be explained as Turkish women are not informed about the consequences of vaginal birth, and they only realize this situation when they are symptomatic.

It is a well-known fact that parity increases urinary incontinence in premenopausal women. The first delivery has the most important effect on incontinence, whereas subsequent deliveries have a small but ongoing effect $(11,12)$. We have found that parity has a significant effect on PRKS, and there is a significant difference between PRKS of primiparous and multiparous women. Although PRKS was significantly lower in patients with a history of cesarean birth than in those with vaginal birth, there was also a significant difference between nulliparous women and participants with a history of cesarean birth, with nulliparous women with lower

Table 5. The correlation analysis between parity and PRKS

\begin{tabular}{lccc} 
& $\mathbf{n}$ & PRKS (mean \pm SD) & p \\
\hline Nulliparity & 249 & $2.7 \pm 1.76$ & 0.0001 \\
\hline Primiparity & 167 & $3.49 \pm 1.5^{\alpha}$ & \\
$\geq 2$ parity & 900 & $5.84 \pm 2.29^{\beta, \gamma}$ & \\
${ }^{\alpha} p=0.001$, nulliparity/primiparity; ${ }^{\beta} p=0.0001$, nulliparity/multiparity; \\
${ }^{\gamma} p=0.0001$, primiparity/multiparity; PRKS: pelvic risk knowledge score
\end{tabular}

Table 6. The correlation analysis between mode of delivery and PRKS

\begin{tabular}{|llccc|}
\hline & & $\mathbf{n}$ & PRKS $($ mean \pm SD $)$ & p \\
\hline Mode of delivery & Vaginal birth & 808 & $5.58 \pm 2.38$ & 0.006 \\
\cline { 2 - 5 } & C-section & 259 & $5.14 \pm 2.22$ & \\
\hline Nulliparity & 249 & $2.70 \pm 1.76$ & 0.0001 \\
\hline & C-section & 195 & $4.83 \pm 2.18$ & \\
\hline
\end{tabular}

PRKS: pelvic risk knowledge score; SD: standard deviation 
PRKS. This result can be attributed to the negative impact of pregnancy on pelvic floor muscles and urinary incontinence.

The present study has some limitations. First, although the small sample size can be a limitation of the study, our hospital is located in the largest region of Turkey and covers a population who had migrated from different parts of the country. Second, there is a lack of Turkish validation of PRKS. It can be validated after encouraging results of our results in future studies.

\section{Conclusion}

The results of the present study indicate that parity and lower urinary tract symptoms have a significant correlation. Although pelvic muscle exercises are recommended as the first-line management for the prevention of SUI during pregnancy and postpartum period, the knowledge of the Turkish population on this issue is poor, and health care providers should exert more effort to raise awareness in society.

Ethics Committee Approval: Ethics committee approval was received for this study from the Ethics Committee of Health Sciences University Bakirköy Dr. Sadi Konuk Training and Research Hospital (2014/27).

Informed Consent: Written informed consent was obtained from patients and patient's parents who participated in this study.

Peer-review: Externally peer-reviewed.

Author Contributions: Concept - M.E., C.K.; Design - M.E., H.C.; Supervision - C.K., L.Y.; Resources - G.U., H.C.; Materials - G.U., H.C.; Data Collection and/or Processing - G.U., E.Ö.; Analysis and/or Interpretation - G.U., E.Ö.; Literature Search - E.Ö., C.K.; Writing Manuscript - L.Y., M.E.; Critical Review - M.E., H.C.

Conflict of Interest: The authors have no conflict of interest to declare.

Financial Disclosure: The authors declared that this study has received no financial support.

\section{References}

1. Memon $\mathrm{H}$, Handa VL. Pelvic floor disorders following vaginal or cesarean delivery. Curr Opin Obstet Gynecol 2012; 24: 349-54. [CrossRef]
2. MacLennan AH, Taylor AW, Wilson DH, Wilson D. The prevalence of pelvic floor disorders and their relationship to gender, age, parity and mode of delivery. BJOG 2000; 107:1460-70. [CrossRef]

3. Rortveit G, Hannestad YS, Daltveit AK, Hunskaar S. Age-and typedependent effects of parity on urinary incontinence: the Norwegian EPINCONT study. Obstet Gynecol 2001; 98: 1004-10. [CrossRef]

4. Haylen BT, de Ridder D, Freeman RM, Swift SE, Berghmans B, Lee J, et al. An international urogynecological association (IUGA)/international continence society (ICS) joint report on the terminology for female pelvic floor dysfunction. Int Urogynecol J 2010; 21: 5-26. [CrossRef]

5. National Institute for Health and Clinical Excellence (NICE). Urinary incontinence in women: management. 2013 Sept (cited 2015 October 30). Available from: URL: www.nice.org.uk/ guidance/cg171/resources/urinary-incontinence-in-women-management- 35109747194821.

6. Boyle R, Hay-Smith EJ, Cody JD, Mørkved S. Pelvic floor muscle training for prevention and treatment of urinary and faecal incontinence in antenatal and postnatal women. a short version Cochrane review. Neurourol Urodyn 2014; 33: 269-76. [CrossRef]

7. Mørkved S, Bø K. Effect of pelvic floor muscle training during pregnancy and after childbirth on prevention and treatment of urinary incontinence: a systematic review. Br J Sports Med 2013; 48: 299-310. [CrossRef]

8. Dunbar A, Ernst A, Matthews C, Ramakrishnan V. Understanding Vaginal Childbirth: What Do Women Know About the Consequences of Vaginal Childbirth on Pelvic Floor Health? J Womens Health Phys Therap 2011; 35: 51-6 [CrossRef]

9. Yıldız Ș, Çaypınar SS, Cengiz H, Dağdeviren H, Kanawati A. Awareness and perceptions of Turkish women towards delivery methods J. Clin and Exp Invest 2014; 5: 173-8.

10. Woodley SJ, Boyle R, Cody JD, Mørkved S, Hay-Smith EJC. Pelvic floor muscle training for prevention and treatment of urinary and fecal incontinence in antenatal and postnatal women Cochrane Database Syst Rev 2017; 12: CD007471.

11. Leijonhufvud A, Lundholm C, Cnattingius S, Granath F, Andolf E, Altman D. Risks of stress urinary incontinence and pelvic organ prolapse surgery in relation to mode of childbirth. Am J Obstet Gynecol 2011; 204: 70. [CrossRef]

12. Handa VL, Blomquist JL, Knoepp LR, Hoskey KA, McDermott KC, Muñoz A. Pelvic Floor Disorders 5-10 years after vaginal or cesarean childbirth. Obstet Gynecol 2011; 118: 777-84. [CrossRef]

Cite this article as: Ekin M, Kaya C, Öztürk E, Cengiz H, Uzer G, Yașar L. The Level of Knowledge of Pelvic Floor Dysfunction After Delivery in Women who Attended to a Tertiary Center. ístanbul Med J 2018; 19(4): 277-80. 